Ilango Kaliappan et al / Int. J. Res. Ayurveda Pharm. 4(5), Sep - Oct 2013

Review Article

www.ijrap.net

\title{
EMERGING NEED OF PHARMACOKINETICS IN AYURVEDIC SYSTEM OF MEDICINE
}

Ilango Kaliappan ${ }^{1}$, Ananth Kumar Kammalla ${ }^{1}$, Mohan Kumar Ramasamy ${ }^{1}$, Aruna Agrawal ${ }^{3}$, Govind Prasad Dubey ${ }^{2}$

${ }^{1}$ Interdisciplinary School of Indian System of Medicine, SRM University, Kattankulathur, Tamil Nadu, India

${ }^{2}$ National Facility for Tribal and Herbal Medicine, Institute of Medical sciences, Banaras Hindu University, Varanasi, India

${ }^{3}$ Faculty of Ayurveda, Institute of Medical sciences, Banaras Hindu University, Varanasi, India

Received on: 08/08/13 Revised on: 20/09/13 Accepted on: 10/10/13

\author{
*Corresponding author \\ E-mail: Ilangok67@gmail.com \\ DOI: $10.7897 / 2277-4343.04503$ \\ Published by Moksha Publishing House. Website www.mokshaph.com \\ All rights reserved.
}

\section{ABSTRACT}

Ayurveda is the most ancient system of traditional medicine of the world has been practicing in India. It has been facing constant challenges like standardization and pharmacokinetic profile of biomarkers in the Ayurvedic formulations. Due to these challenges there will be a potential decrease in the global herbal market. Presently Indian herbal market is about US \$1.1 billion whereas Chinese herbal market is about US \$10 billion per annum. Thus there is an urgent need of standardization and pharmacokinetics of the Ayurvedic formulations in order to achieve the uphold position in the global market. Pharmacokinetics which deals with the absorption, distribution, metabolism and excretion of the biomarkers or the new drug entity is the one of the regulatory requirement for an investigational new drug approval. Bioactive guided pharmacokinetic approach method is needed for Ayurvedic system of medicine to determine the pharmacokinetics of relevant markers in the formulation having number of markers. Also non compartmental analysis method should be applied for the analysis of pharmacokinetics of biomarkers from Ayurvedic formulations for successful pharmacokinetic evaluation. In this review we have explored the importance of pharmacokinetics in Ayurvedic system of medicine and integrated approaches for the pharmacokinetics in Ayurvedic system of medicine.

Keywords: Ayurveda, Pharmacokinetics, Herbal market, Non compartmental model.

\section{INTRODUCTION}

India is one of the 12 mega biodiversity zone covering 2.4 $\%$ of world's area but with $8 \%$ of global biodiversity. It includes 15 agro-climatic zones containing about 47,000 plant species including nearly 15,000 medicinal plants ${ }^{1}$. Several traditional healthcare systems exist in India from centuries and out of all the traditional practices, Ayurveda, Yoga and Naturopathy, Unani, Siddha and Homeopathy are the official traditional systems of medicine. These systems are collectively known as Indian Systems of Medicine (ISM) ${ }^{2}$. Ayurveda is the most ancient system of traditional medicine of the world, has been practiced in Indian subcontinent since $5000 \mathrm{BC}^{3,4}$. It is a holistic approach towards life, health and disease management through medicinal herbs, minerals, diet, lifestyle and spirituality. Ayurveda was developed through daily experiences and mutual relationship between people and nature, and thus not only cure diseases but also prevent disease, maintain health and promote longevity ${ }^{5}$. This holistic system looks at the whole person as a combination of body, mind and soul ${ }^{6}$. Therefore, it is a comprehensive and integral medicinal system, gift of Indian sages to mankind ${ }^{7}$. Ayurveda is widely respected for its uniqueness and global acceptance as it offers natural ways to treat diseases and promote healthcare ${ }^{8}$. Generally Ayurvedic formulations are multicomponent mixtures, containing plant and animal derived products, minerals and metals. Ancient's texts like 'Rig Veda', Atharva Veda, and Official compendia like Ayurvedic Pharmacopoeia, Ayurvedic Formulary show dominance of plant - derived products ${ }^{9}$. Variations in geographical landscaping and bio diversities in the Indian subcontinent have helped to develop the use of a variety of plant species and other natural resources for health care and contributed to the Materia Medica of traditional systems of medicine. More than 25000 single or poly herbal formulations are used by the tribal and rural population in India ${ }^{10}$. Export - Imports bank reports reveals that the global trade of plant derived and plant originated products is of around US \$62 billion (with growth of $7 \%$ per annum) where India holds stake US \$1 billion $^{11}$. There is an urgent need to cherish these in both the national and international perspectives for benefit of mankind. Apart from healthcare, medicinal plant trade is an important alternative income generating source for under-privileged communities. Thus there is an urgent need of the scientific base evaluation of an Ayurvedic system of medicine for accepting international regulatory guideline to get drug approval status. In this review we summarized the international market status of Indian herbals and its constant challenges and also integrated approaches for the pharmacokinetics in the Ayurvedic system of medicine.

\section{International market scenario of Indian medicinal plants}

Global market of Herbal industry shares about US \$62 billion $^{12}$. The value of botanical related trade in India is about US \$10 billion per annum with annual export of US $\$ 1.1$ billion $^{13}$ while China's annual herb drug production is worth US $\$ 48$ billion with export of US $\$ 3.6$ billion $^{14}$. India seems to be lagging behind and is ranked third in the herbal medicine category, with less than $2 \%$ global market share. According to an Ayurveda expert, Chinese herbal medicines, which rarely contain $10 \%$ scientific base when compared with the Indian Ayurvedic system, 
are doing better than India by 50 -fold ${ }^{15,16}$. India had failed to make an impact in the global share market with Ayurvedic system of medicine and the gap between Indian and other countries is extending rapidly in the herbal field ${ }^{17}$. The export of herbal medicine from India is insignificant despite the fact that country has a rich traditional knowledge and heritage of herbal medicine ${ }^{18}$. The constant challenges for the Ayurvedic system of medicine are lack of standardization, quality control and pharmacokinetic profile of bioactive molecules. Although the herbal medicines have been used for thousands of years, basic research programmers need to be focused on the quality assurance. To overcome contaminations from pesticide residues and heavy metals there should be a control measures to implement necessary Standard Operating Procedures (SOP) at source. Good laboratory practices (GLP), Good Agricultural practices (GAP) and Good Manufacturing practices (GMP) are needed to produce good quality medicinal products. Also scientific based complete pharmacological data is required for the Ayurvedic system of medicine. Without all these measures, it is impossible to realize the dream of having a major share of herbal drug industry despite having gold mine of well documented and well-practiced knowledge of traditional herbal medicines. Both India and China having great traditional systems of medicines with strong philosophical basis and could play an important role in new therapies, drug discovery and development process ${ }^{19}$.

\section{Challenges to Ayurvedic system of medicine}

Although Ayurvedic medicines are widely used for the prevention, diagnosis, treatment and management of diseases, quality control and proper regulation worldwide are still a big challenge as shown in Figure 1. Widespread and growing use of botanicals has created a global challenge in terms of quality, safety and efficacy. Scientific validation and standardization of herbal medicines is needed for the future advancement of traditional medicine. Proper use of products of assured quality could also do much to reduce any risks associated with herbal medicine. However, regulation and legislation of herbal medicines has been enacted in very few countries. Most of the countries do not have any proper regulation on botanicals and the quality of herbal products sold is generally not guaranteed ${ }^{20,21}$.

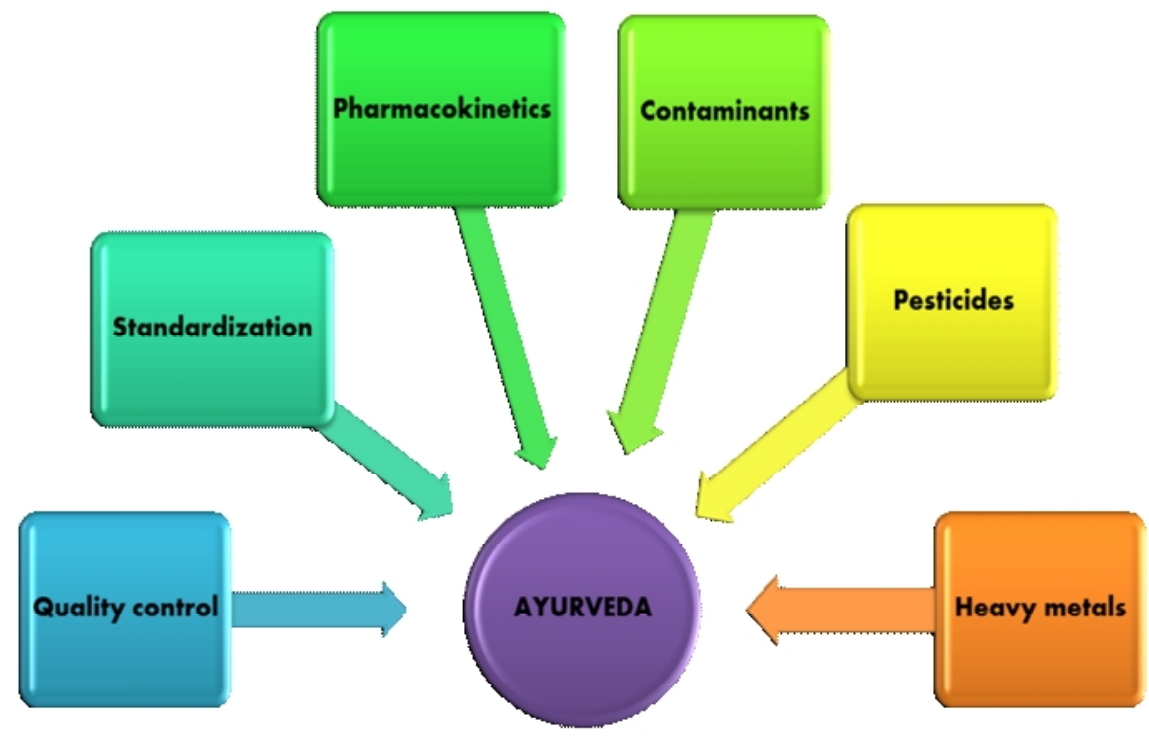

Figure 1: Constant challenges for the Ayurvedic system of medicine

Establishing the pharmacological basis of efficacy of herbal products is constant challenge due to their complex composition and the ever-increasing list of their putatively active constituents. In vitro assays normally are cheap and relatively easy to perform, but the relevance of the findings is based on a sufficient concentration of active constituents at the site of action. Of particular interest is the question of bioavailability to assess to what degree and how fast compounds are absorbed after oral administration of herbal products. Of further interest are the elucidation of metabolic pathways which yields potentially new active compounds and the assessment of elimination route and their kinetics. Thus the pharmacokinetic data will become an important link data from pharmacological assays and clinical effects. There is usually detailed information available about the pharmacokinetics and bio pharmaceutics of chemical active pharmaceutical ingredients but it is absolutely lacking in the case of Ayurvedic medicine. The reason for that lies in the complexity of extracts as multicomponent mixtures and lack of knowledge of the active principles. With increasing knowledge of putatively active compounds and availability of highly selective and sensitive analytical methods pharmacokinetics can be evaluated for the Ayurvedic formulations. Thus this review promotes the urgent need of pharmacokinetics in the Ayurvedic system of medicine to achieve the uphold position in the global market. 
Pharmacokinetics: A missing critical step in the Ayurvedic system of medicine

Pharmacokinetics of the new drug entity is one of the regulatory requirements for an investigational new drug approval. However, for the majority of Ayurvedic formulations used in the traditional or conventional medical practice, data on their disposition and biological fate in human are lacking. It is vital in the drug development process to understand the absorption, distribution, metabolism and excretion (ADME) of an active molecule from these formulations and how they interact with conventional drugs before their launch in the market in order to ensure the rational use of herbal medicines. Pharmacokinetics in the Ayurvedic system are largely ignored due to the rigor, cost and time consumption of the drug development process. One of the major reasons is that for most of these multicomponent mixtures their active ingredients are not known. In addition, there is a difficulty of measuring the quantities of the active constituents in systemic circulations due to very low concentrations, arising from the very small amount per dose in the final product. These challenges have led to the situation that most herb-drug interaction studies and case reports in the literature only evaluate the outcome of adding an herbal product to an existing conventional drug therapy and monitoring changes in pharmacokinetics and clinical response on the traditional drug $^{22}$. The metabolism of a drug can be altered by another drug or foreign chemical; such interactions are significant in clinical effects. Cytochrome P450 enzymes, a super family of enzymes found mainly in the liver are involved in numerous interactions between drugs food, herbs and other drugs. The observed induction and inhibition of the CYP enzymes by natural products in the presence of prescribed drug has led to the general acceptance that natural therapies can have adverse effects contrary to the popular beliefs in countries where there is an active practice of traditional medicine. Majority of the classes of conventional drugs have been shown to be affected by different types of herbal preparations leading to various consequences, including treatment failure, adverse / toxic effects and even death. In order to improve the safety of Ayurvedic system of medicine, use alongside conventional therapies in public healthcare, it is necessary to know that how the herbal drugs interact with conventional drug, early in the drug development. It is also necessary to predict early so as to eliminate regulatory obstacles and avoid market pressure for recalls that may have been induced by adverse effects linked to interactions. Therefore a better understanding of the pharmacokinetics of Ayurvedic formulations is needed to support the predictability of herb - drug interactions.

\section{Bio-activity guided pharmacokinetic methods for Ayurveda}

Conceptually, all active compounds in a pharmaceutical product that are bioavailable in the systemic circulation can be considered as relevant markers for quality control since such markers import in vivo relevance. Unlike a conventional pharmaceutical product which usually contains one absorbable active compound and is also a designated marker compound for QC, many compounds exist in Ayurvedic formulation. Thus identification do relevant marker (absorbable and bioactive) for Ayurvedic formulation becomes difficult especially if they are determined by an in-vivo approach, e.g. from blood or plasma samples after Ayurvedic formulation administration. The difficulty is primarily technical as it is virtually impossible to distinguish many such markers from hundreds of endogenous chemicals which are also present in the systemic circulation. In addition, determination of specific activity of these marker compounds in vivo not only can be labor intensive but require clinical facility as well as patient informed consent. Thus identification of relevant markers for Ayurvedic formulation is mandatory for better clinical efficacy.
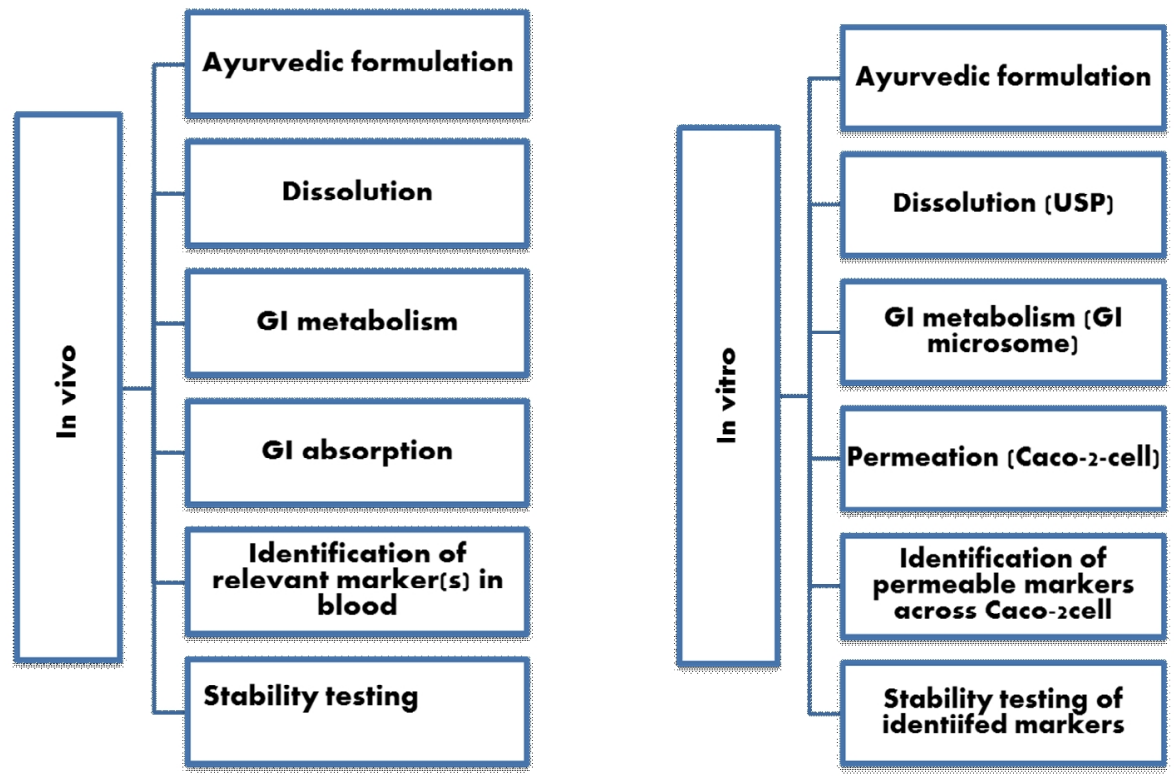

Figure 2: In vitro and in vivo comparison of bioactivity guided pharmacokinetic approach for Ayurvedic formulations 
When Ayurvedic formulations are administered orally which was the most common and convenient route of administration to achieve desirable therapeutic effect the bioactive components must undergo the following bio pharmaceutics/pharmacokinetic processes in the gut; dissolution, metabolism and absorption ${ }^{23}$. Only those active components that are absorbable may be considered as relevant markers since they are capable of contributing to in vivo activity. Thus, identification of absorbable bioactive components using in vitro models that can simulate in vivo PK process may be a practical approach for identifying relevant markers for quality control. Based on this premise, Ling Wanget $\mathrm{al}^{24}$ proposed the following sequential steps for in vitro bio activity guided pharmacokinetic approach that can parallel the in vivo $\mathrm{PK}$ processes (Figure 2). This proposed in vitro approach not only importantly avoids confounding endogenous chemicals present in the plasma but also making analytical separation of multiple active components in Ayurvedic formulation more feasible.

Non compartmental approach to pharmacokinetic analysis of Ayurvedic formulations

Theoretically when the drug is rapidly distributed to all parts of the body, the body behaves as one compartment and the drug profile in the body can be described as onecompartment pharmacokinetic model. On the other hand when the distribution of the drug in a group of tissues or organs is faster than its distribution to other tissues or organs, the body behaves as two different compartments and the drug profile in the body can be described by a two compartment pharmacokinetic model. The body can also behaves as multiple compartments when the drug is distributed to different group of tissues at different rates. The compartmental approach in data analysis sometimes is faced with some difficulties such as when the drug concentration-time profile after intravenous administration is described by a two compartment pharmacokinetic model, but after oral administration of the same drug, the profile is similar to that of the one compartmental model because the rate of absorption and distribution process are not distinctively different. To avoid these difficulties, a different approach, known as the non compartmental approach, may be used for data analysis which can be examined without the need to assume a certain compartmental model ${ }^{25}$. The noncompartmental approach in pharmacokinetic data analysis is based on the statistical moment theory, which has been utilizes in chemical engineering. This theory views the drug molecules in the body as randomly distributed and each molecule has certain probability to be eliminated at certain time $t$. So, according to this theory, the time course for the drug concentration in plasma can be regarded as probability density function. This probability density function multiplied by time raised to certain power $(0,1$ or 2$)$ and integrated over time yields the area under the moment curve. For example, the area under the zero moment curves can be determined from equation 1 , which is equal to the AUC. Also, the area under the first moment curve (AUMC) can be determined according to equation 2. Only the areas under the zero and first moments are utilized in pharmacokinetics because higher moments are subjected to large computational errors.

$$
\text { Area under the zero-moment curve }=\int_{t=0}^{t=\infty} \text { to } \mathrm{Cp}=\int_{\mathrm{t}=0}^{\mathrm{t}=\infty} \mathrm{Cpt}=\mathrm{AUC}
$$

$$
\text { Area under the first-moment curve }=\int_{t=0}^{t=\infty} t 1 \mathrm{Cp} \mathrm{dt}=\int_{t=0}^{t=\infty} t \mathrm{Cp} d t=A U M C
$$

The principle of moment analysis has been utilized to estimate pharmacokinetic parameters such as mean residence time (MRT), drug clearance and the volume of distribution at steady state.

\section{Mean residence time}

The drug molecules are distributed throughout the body after drug administration. Some drug molecules are eliminated from the body faster than other molecules, which stay longer despite the fact that all the molecules are similar. The difference in the residence time for each molecule in the body occurs by chance according to statistical moment theory. The MRT is defined as the average time for the residence of all the drug molecules in the body. MRT can be calculated from the area under zero and first moment curve according to equation 3.

$$
\text { MRT }=\frac{\text { AUMC }}{\text { AUC }}
$$

Where AUMC is the area under the first moment - time curve and AUC is the area under the zero moment time curve or the area under the plasma concentration-time curve. The MRT has units of time.

The absolute bioavailability is determined from the ratio of AUC after oral and IV administration as in equation 4 and the relative bioavailability of two products is determined from the ratio of AUC for the two different oral products as in the equation 5 .

$$
\begin{gathered}
F_{\text {Absolute }}=\frac{\text { AUC }_{\text {oral }}}{\text { AUC }_{i v}} \\
F_{\text {Relative }}=\frac{\text { AUC }_{p_{\text {vuluuiLA }}}}{\text { AUC }_{p_{\text {roduct }} \bar{s}}}
\end{gathered}
$$


The drug clearance can be determined after i.v. administration from the dose and the AUC as in equation 6 and after oral administration as in equation 7.

$$
\begin{aligned}
& \mathrm{CL}_{\mathrm{T}}=\frac{\text { Dose }_{\mathrm{lV}}}{\mathrm{AUC}_{\mathrm{fv}}} \\
& \frac{\mathrm{CL}_{\mathrm{T}}}{\mathrm{F}}=\frac{\text { Dose oral }_{\text {or }}}{\mathrm{AUC}_{\text {oral }}}
\end{aligned}
$$

Using non compartmental approach for pharmacokinetic data analysis have successfully evaluated for the pharmacokinetics of particular biomarkers for Visnagin and Ammi visnaga ${ }^{26}$, Senkyunolide $\mathrm{I}^{27}$ and many Chinese formulations.

\section{CONCLUSION}

Recognition of the medical and health benefits of Ayurvedic system of medicine with health claims is growing worldwide. Pharmaceutical research must go beyond focusing on pharmacological efficacy of Ayurvedic formulations mainly in studies that improves their effectiveness in order to fully benefit humanity from their inherent therapeutic potentials. With advance in instrumentation like HPLC/MS/MS and HPLC/NMR as increasing number of components are being identified from starting material used for preparation of those products. India needs a clear policy for such integration without compromise on the strategies that are sciencebased. Efforts are needed to establish and validate pharmaco-epidemiological evidence regarding safety and practice of Ayurvedic medicines. Pharmacokinetic data of biomarkers contribute considerably to the scientific assessment of the various claims of herbal products, which are increasingly marketed with curative claims worldwide. While a registration process reviewing quality, safety and efficacy of herbal medicinal products is established in curtained European countries and also the FDA is considering to review certain botanicals via the IND/NDA (Investigational New Drug/New Drug Application) process. In summary Indian Ayurvedic system of medicine having great traditional with strong philosophical basis and could play an important role in new therapies, drug discovery and development process. Ayurvedic system of medicine with strong scientific evidence will be top leader in the global market.

\section{REFERENCES}

1. WHO. Country cooperation Strategy, India, Supplement on Traditional Medicine Indian, Editor. New Delhi: World Health Organisation; 2007.

2. AYUSH. AYUSH in India, Planning and Evaluation Cell. In Department of Ayurveda: Ministry of Health and Family welfare; 2011.

3. Dasgupta S. A history of Indian philosophy New Delhi: Motilal Banarsidass Publishers Private Limited; 1992.

4. Mukherjee PK, Wahile A. Integrated approaches towards drug development from Ayurveda and other Indian system of mediicnes. J Ethanopharmacol 2006; 103: 25-35. http://dx.doi.org/10.1016 j.jep.2005.09.024 PMid:16271286

5. Fradwley D, Ranade S. Ayurveda, Nature's Medicine USA: Lotus press; 2001.
6. Atreya. Perfect Balance: Ayurvedic Nutrition for Mind, Body and Soul New York: Penguin Penguin Putnam Inc; 2002.

7. Ninivaggi FJ. Ayurveda: A Comprehensive Guide to Traditional Indian medicine for the West Maryland: Rowman and Littlefield Publisher, Inc; 2008. PMid:18939687

8. Mukherjee PK, Houghton PJ. The worldwide phenomenon of increased use of herbal products: oppurtunity and threats. In Houghton PJ. Evaluation of Herbal Medicinal Products Perspectives on Quality, Safety and Efficacy. Great Britain: Pharmaceutical Press, Royal Pharmaceutical Society of Great Britain; 2009. p. 3-12.

9. India Apo. Ayurvedic Pharmacopoeia of India Government of India MoHaFW, editor. New Delhi: Department of Indian system of Medicine and Homeopathy; 2001.

10. Mukherjee PK, Wahile A. Integrated approaches towards drug development and other Indian system of medicines. J Ethnopharmacol 2006; 103: 25-35. http://dx.doi.org/10.1016 j.jep.2005.09.024 PMid:16271286

11. Raskin I, Ribinicky DM, Komarnytsky S, IIic N, Poulev A, Borisjuk $\mathrm{N}$ et al. Plants and human health in the twenty-first century. Trends Biotechnol 2002; 20: 522-531. http://dx.doi org/10.1016/S0167-7799(02)02080-2

12. World Health Oraganisation. Report of the inter-regional workshop on intellectual property rights in the context of traditinal medicine. Bangkok; 2000.

13. Singh J, Singh A, Khanuja S. Medicinal plants: India's opportunities. Pharma Bioworld 2003; 1: 59-66.

14. Handa S. Indian efforts for quality controal and standardization of herbal drugs/products. In Proceeedings of the 1st joint workshop on quality control and standardization of traditinal medicine - IndoChina experience; 2004. p. 8-10.

15. Lad V. The Human Constitution Ayurveda: The science of self healing.: Wilmot Lotus Press; 1985.

16. Ayurveda 101 and related medicines. Frontline World. [Online]. Available from: http://www.pbd.org/frontlineworld/ stories/india 701/; 2008.

17. Valiathan MS. Healing Plants. Curr sci 1998; 75: 1122-1127.

18. Kamboj VP. Herbal medicine. Curr sci 2000; 78: 35-39.

19. Aneesh TP, Hisham Mohame, Sonal Sekhar M, Madhu Manjusree and Deepa TV. International market scenario of traditinal Indian herbal drugs - India declining. Int J Green Pharm; 2009. p. 184-190.

20. World Health Organisation. WHO Traditional Medicine Strategy, Geneva: World Health Oraganization; 2002.

21. Warude D, Patwardhan B. Botanicals:quality and regulatory issues J Sci Ind Res 2005; 64: 83-92.

22. Williamson E, Evans F. Cannabinoids in clinical practice. Drugs 2000; 60: 1305-1314. http://dx.doi.org/10.2165/00003495-200 060060-00005

23. Shargel L, Wu Pong S, Yu ABC. Applied Biopharmaceutics and Pharmacokinetics New York: The Mc Graw Hill Companies,Inc; 2004.

24. Ling W, Zhijun W, Siukwan W, Clara BSL, Xiao C, Min H, et al. A bio-activity guided in vitro pharamcokinetic method to improve the quality control of Chinese medicines, application to SI Wu Tang. Int J Pharm 2011; 406: 99-105. http://dx.doi.org/10.1016/j.ijpharm. 2011.01.001 PMid:21219992

25. A Hedaya M. Basic pharmacokinetics New York: Taylor and Francis Group; 2010.

26. Haug KG, Benjamin W, Guenther H, Veronika B. Pharmacokinetic Evaluation of visnagin and Ammi visnaga Aqueous extract after oral admiinstraion in Rats. Planta Med 2012; 78: 1831-1836. http://dx. doi.org/10.1055/s-0032-1315393 PMid:23096256

27. Chun Yong H, Shou Wang, Yi Feng, Shuang Liang, Xiao Lin, De Sheng $X$, et al. Pharmacokientics, tissue distribution and metabolism of senkyunolide I, a major bioactive component in Ligusticum chuanxiong Hort. Umbelliferae. J Ethnopharmacol 2012; 142: 706-713. http://dx. doi.org/10.1016/j.jep.2012.05.047 PMid:22668502

Cite this article as:

Ilango Kaliappan, Ananth Kumar Kammalla, Mohan Kumar Ramasamy, Aruna Agrawal, Govind Prasad Dubey. Emerging need of pharmacokinetics in Ayurvedic system of medicine. Int. J. Res. Ayurveda Pharm. 2013;4(5):647-651 http://dx.doi.org/10.7897/2277$\underline{4343.04503}$ 